\title{
Role of organic matter on electroosmotic properties and ionic modification of organic soils
}

\begin{abstract}
Organic soils represent accumulations of disintegrated plant remains that have been preserved under condition of incomplete aeration and high water content. Using electrokinetic (EK) techniques to improve organic soils entails evaluating factors that define geoenvironmental behavior of organic soils. Electroosmotic properties were investigated to conceptualize EK phenomena. The results of the study showed that the zeta potential, specific surface area, water contents, and liquid limit (LL) increased as the organic content increased. The natural zeta potential of the organic soils varied from -11.2 to $-20.8 \mathrm{mV}$ according to the organic content, degree of humification, and soil $\mathrm{pH}$. The negative charge in organic soils is highly $\mathrm{pH}$ dependent and surface charge is dropped to zero at $\mathrm{pH} 2.3$ to 3.5. The greater degree of humification resulted in the higher zeta potential and lower $\mathrm{pH}$ at the iso-electric point. This paper also gives some insights on ionic modification, which is an innovative method that could be employed to change the water holding capacity of organic soils and its consistency. The $\mathrm{Fe}+3$ ions had 20 to $30 \%$ pronounced effect on decreasing LL according to the organic content. Increasing the cation valence reduces the affinity of water to the organic soil surface and decreases LL as a major part of Atterberg's consistency system. By the sound of peat and its environment, there is a great likelihood that EK techniques could be used to resolve peat's difficulties from the geoenvironmental viewpoint.
\end{abstract}

Keyword: CEC, EK phenomena, homoionic modification, organic soils, peat soils, zeta potential 